NASA/TM-1998-208830

$$
\begin{aligned}
& N=0 \\
& 011473
\end{aligned}
$$

\title{
"2001: A Space Odyssey" Revisited -- The Feasibility of 24 Hour Commuter Flights to the Moon Using NTR Propulsion with LUNOX Afterburners
}

Stanley K. Borowski and Leonard A. Dudzinski Lewis Research Center, Cleveland, Ohio

Prepared for the

33rd Joint Propulsion Conference

cosponsored by the AIAA, ASME, SAE, and ASEE

Seattle, Washington, July 6-9, 1997

National Aeronautics and

Space Administration

Lewis Research Center 


\section{Acknowledgments}

The authors wish to express thanks to their respective organizations for support during the course of this study. One of the authors, Dr. Stanley Borowski, would like to express his gratitude to the following individuals for their contributions to this paper: Kriss Kennedy (NASA/JSC) for his preliminary assessment of the PTM mass; noted space artist, Pat Rawlings (SAIC) for artwork depicted on the cover and in Figures 3, 8, 10, and 11;

Melissa McGuire (Analex) for her assistance in the preparation of tables and figures used in this paper.

Available from

NASA Center for Aerospace Information

7121 Standard Drive

Hanover, MD 21076

Price Code: A03

National Technical Information Service 5285 Port Royal Road

Springfield, VA 22100

Price Code: A03 


\title{
"2001: A SPACE ODYSSEY" REVISITED--THE FEASIBILITY OF 24 HOUR COMMUTER FLIGHTS TO THE MOON USING NTR PROPULSION WITH LUNOX AFTERBURNERS
}

\author{
Stanley K. Borowski" and Leonard A. Dudzinski"* \\ NASA Lewis Research Center \\ Cleveland, $\mathrm{OH} 44135$ \\ (216) $977-7091$ and -7107
}

\section{ABSTRACT}

The prospects for " 24 hour" commuter flights to the Moon, similar to that portrayed in 2001: A Space Odyssey but on a more Spartan scale, are examined using two near term, "high leverage" technologies---liquid oxygen (LOX)-augmented nuclear thermal rocket (NTR) propulsion and "lunar-derived" oxygen (LUNOX) production. Ironrich volcanic glass, or "orange soil," discovered during the Apollo 17 mission to Taurus-Littrow, has produced a $4 \%$ oxygen yield in recent NASA experiments using hydrogen reduction. LUNOX development and utilization would eliminate the need to transport oxygen supplies from Earth and is expected to dramatically reduce the size, cost and complexity of space transportation systems. The LOX-augmented NTR concept (LANTR) exploits the high performance capability of the conventional liquid hydrogen $\left(\mathrm{LH}_{2}\right)$-cooled NTR and the mission leverage provided by LUNOX in a unique way. LANTR utilizes the large divergent section of its nozzle as an "afterburner" into which oxygen is injected and supersonically combusted with nuclear preheated hydrogen emerging from the engine's choked sonic throat--essentially "scramjet propulsion in reverse." By varying the oxygen-to-hydrogen mixture ratio, the LANTR engine can operate over a wide range of thrust and specific impulse (Isp) values while the reactor core power level remains relatively constant. The thrust augmentation feature of LANTR means that "big engine" performance can be obtained using smaller, more affordable, easier to test NTR engines. The use of high-density LOX in place of low-density $\mathrm{LH}_{2}$ also reduces hydrogen mass and tank volume resulting in smaller space vehicles. An implementation strategy and evolutionary lunar mission architecture is outlined which requires only Shuttle C or "in-line" Shuttle-derived launch

"Ph.D./Nuclear Engineering, Senior Member AIAA **Aerospace Engineer, Member AIAA vehicles, and utilizes conventional NTR-powered lunar transfer vehicles (LTVs), operating in an "expendable mode" initially, to maximize delivered surface payload on each mission. The increased payload is dedicated to installing "modular" LUNOX production units with the intent of supplying LUNOX to lunar landing vehicles (LLVs) and then LTVs at the earliest possible opportunity. Once LUNOX becomes available in low lunar orbit (LLO), monopropellant NTRs would be outfitted with an oxygen propellant module, feed system and afterburner nozzle for "bipropellant" operation. Transition to a "reusable" mission architecture now occurs with smaller, LANTR-powered LTVs delivering $\sim 400 \%$ more payload on each piloted round trip mission than earlier expendable "all $\mathrm{LH}_{2}$ " NTR systems. As initial lunar outposts grow to eventual lunar settlements and LUNOX production capacity increases, the LANTR concept can enable a rapid "commuter" shuttle capable of 24 hour "one way" trips to and from the Moon. A vast deposit of "iron-rich" volcanic glass beads identified at just one candidate site--located at the southeastern edge of Mare Serenitatis--could supply sufficient LUNOX to support daily commuter flights to the Moon for the next 9000 years!

\section{INTRODUCTION}

Approximately 30 years have passed since the debut of Stanley Kubrick and Arthur C. Clarke's hit movie 2001: A Space Odyssey. ${ }^{1}$ For many of us this film brought to life the exciting possibilities awaiting humankind beyond the Apollo program-images of commercial spaceplanes, large orbiting space stations and commuter flights to sprawling settlements on the Moon. Less than six months after experiencing the thrill of Dr. Heywood Floyd's commuter flight to the Moon on the big screen, Apollo 8 would orbit our celestial neighbor ten times on Christmas Eve, followed seven months 
later by the historic lunar landing mission of Apollo 11. For the authors, the images of the Apollo astronauts, their spacecraft and the stunning alien landscapes of Hadley Rille, Descartes and the Taurus-Littrow valley, all there for the taking, imprinted on our minds a future vision of lunar settlement no less dramatic than that portrayed in 2001. After all NASA would have nearly 30 years to develop the necessary technologies. Unfortunately, national support and public interest in the Apollo program soon waned, Apollo missions 18, 19 and 20 were canceled, and the resources for a post-Apollo program that envisioned artificial gravity space stations in both Earth and lunar orbit, a permanent lunar base and a nuclear rocketpowered human mission to Mars by 1981 never materialized.

Today, with 2001 just 4 years away, the images in Kubrick and Clarke's film seem very distant, and 2100: A Space Odyssey a more appropriate title for the movie. Although NASA no longer possesses the systems to send humans to the Moon, it is poised to begin construction of the International Space Station (ISS) ${ }^{2}$ and is currently engaged in a cooperative agreement with industry partner, Lockheed Martin, to demonstrate the technology for a single-stage-to-orbit reusable launch vehicle $(R L V)^{3}$. Beyond the ISS, the Agency's strategic plan for the Human Exploration and Development of Space (HEDS) ${ }^{4}$ envisions the development and utilization of extraterrestrial resources and revolutionary propulsion technologies to provide routine and affordable human space travel to the Moon initially, and then Mars. However, flat or declining budgets for the foreseeable future pose a serious threat to NASA's ability to develop the high leverage technologies it needs to open the space frontier to the public sector.

This paper discusses two key technologies-"lunar-derived" liquid oxygen (LUNOX) production and LOX-augmented nuclear thermal rocket (LANTR) propulsion. These technologies can be developed in the next 10 to 15 years and can provide the basis for an "economical" lunar transportation system (LTS), that can evolve with time to rival the operational capabilities presented in 2001 albeit on a more "Spartan" scale. The LUNOX extraction process, system mass and power requirements, and features of a commercial LUNOX production facility are discussed first. This is followed by a description of the LANTR concept and a discussion of its operational and performance characteristics. An implementation strategy, along with mission and transportation system ground rules and assumptions, is then presented and used in an evolutionary lunar mission architecture that compares chemical and NTR. powered lunar transportation vehicles operating without and with LUNOX. A typical "24 hour" commuter flight to the Moon is then described which includes the mission $\Delta V$ estimates, a description of the LANTR-powered commuter shuttle, and the requirements on the LUNOX production facility needed to support weekly flights to the Moon. The paper concludes with a brief discussion of the potential benefits of LANTR propulsion for human missions to Mars and beyond.

LUNOX: "THE MOON'S FIRST COMMERCIAL PRODUCT"

"Lunar-derived" oxygen has been frequently cited 5 as the most promising initial resource to be developed on the lunar surface. By providing a local source of oxygen for life support systems, fuel cells and the "oxygen-rich" chemical rocket engines used on lunar landing vehicles, initial mass in low Earth orbit (IMLEO), launch costs and LTS size and complexity can all be reduced. Greater quantities of high value cargo (e.g., people, processing equipment and scientific instruments) can also be transported in place of bulk LOX propellant further reducing LTS costs.

Another important reason for considering lunar oxygen as a potential commercial product is its abundance. Nearly half the mass of Moon's surface material is oxygen 5 and a variety of techniques 6 have been identified for its extraction. Hydrogen reduction of iron oxide in the mineral "ilmenite" $\left(\mathrm{FeTiO}_{3}\right)$ has received considerable attention in the past. 7,8 The reduction process produces iron metal, titanium oxide and high temperature water vapor which is subsequently electrolyzed to produce the oxygen resource and the hydrogen catalyst. Conceptual design studies 7,8 of LUNOX production facilities using an "ilmenite-rich" basalt (lunar rock) feedstock indicated oxygen extraction efficiencies of $\sim 1 \%$ and a mining requirement of $-186 \mathrm{t}$ of lunar material per ton of LUNOX produced (assuming a $50 \%$ basalt content in the mined material). Using lower ilmenite content lunar soil or "regolith" as feedstock eliminated the need to crush and grind tons of rock for ilmenite 
extraction but it increased the mining mass ratio to $\sim 327 t$ of soil per ton of LUNOX. Preliminary estimates ${ }^{7}$ of LUNOX plant mass and power levels for a soil feedstock system are shown in Figures 1 and 2 as a function of the annual production rate.

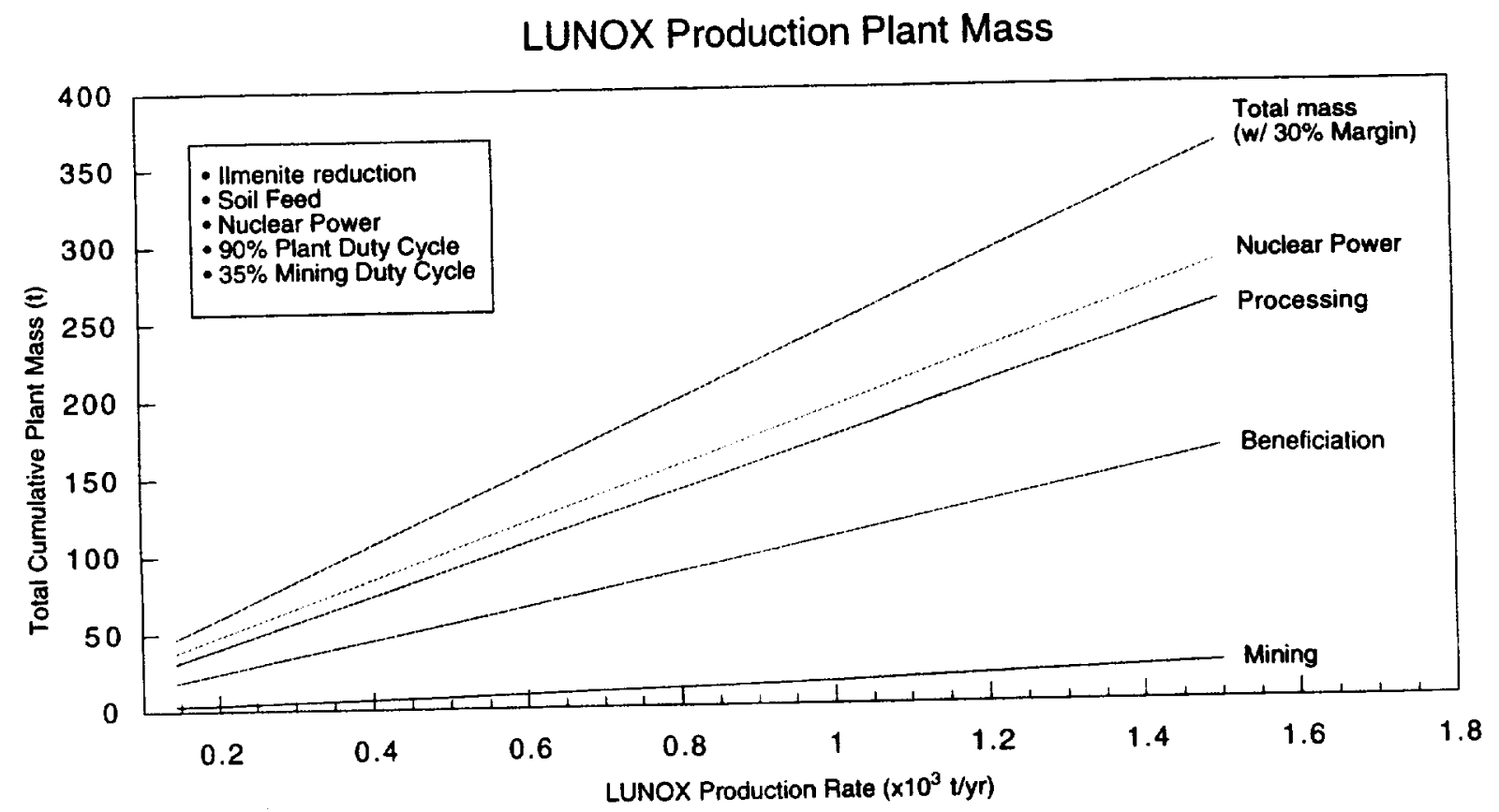

Fig. 1 Variation of LUNOX Production Plant Component Mass with Annual Production Rate.

\section{LUNOX Production Plant Power}

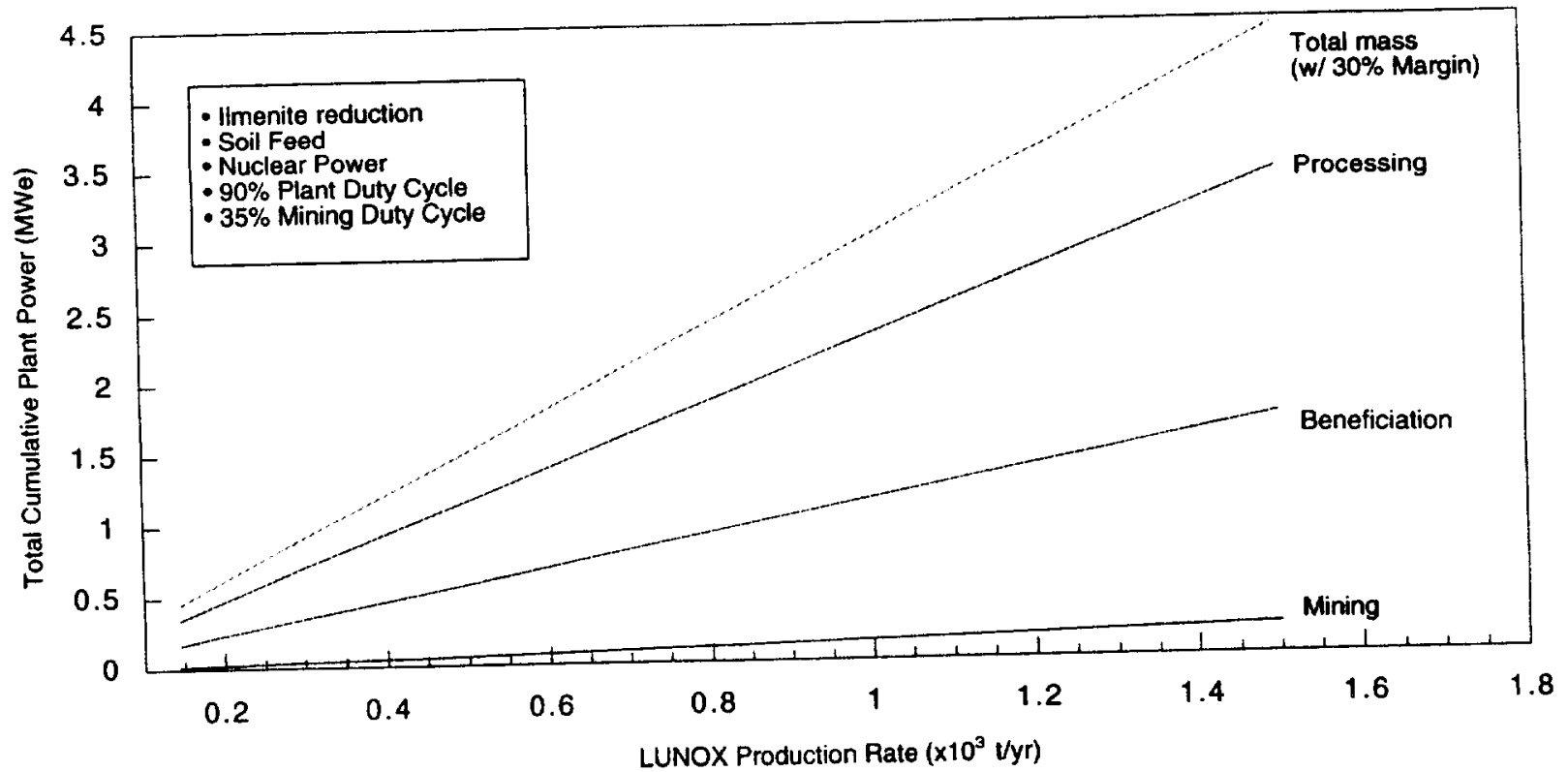

Fig. 2 Variation of LUNOX Production Plant Power with Annual Production Rate. 
Recent reduction experiments $9,10,11$ performed at the NASA Johnson Space Center have produced significantly higher oxygen yields ( $\sim 3$ to $4 \%$ ) using samples of "iron-rich" mare soil and volcanic glass, and indicated a direct correlation of oxygen yield with soil iron content. The iron-rich volcanic glass, or "orange soil," discovered during the Apollo 17 mission to the Taurus-Littrow valley 12,13 , is a particularly attractive feedstock option. It exists in large quantities, is fine grained and could be fed directly into a LUNOX production plant with little or no processing prior to reduction. A $4 \%$ oxygen yield also translates into an order of magnitude reduction in the amount of mined material ( $25 \mathrm{t}$ of volcanic glass feedstock per ton of LUNOX) and a lowering of the mass and power requirements for both the production plant and its support vehicles.

How might a commercial LUNOX operation develop? The current RLV program could provide a viable blueprint. An industry-operated, privatelyfinanced venture, with NASA as its initial customer, could accelerate development of the necessary technologies, reduce operating costs to the government, 14 stimulate additional commercial lunar activities and underwrite eventual development of lunar settlements. Commercial operations could also open up space to more private citizens involved in the particular enterprise and lead to an eventual lunar tourism business. Space tourism to low Earth orbit (LEO) has been proposed 15,16 as a large potential private sector market that could enable a commercially viable RLV service. After trips to LEO, the Moon would be the next logical extension of a space tourism industry.

Our vision of a commercial LUNOX enterprise is illustrated in Figure 3. Located near the southeastern edge of Mare Serenitatis (latitude: $\sim 210$ North / longitude: $\sim 290$ East), not far from the Taurus-Littrow valley, lies a vast deposit of iron-rich volcanic glass beads that covers thousands of square kilometers, is tens of meters thick and could yield hundreds of millions of tons of LUNOX. In the left foreground, two lunar industrialists discuss planned expansions at the LUNOX facility, while to the northwest, modular production units, resembling oil rigs on Earth, generate copious amounts of LUNOX which is stored in wellinsulated tanks adjacent to the facility. To the north, a bottom-loaded, "Sikorsky-style" LLV lifts off from the surface carrying a "mobile" LUNOX tanker vehicle to a propellant depot in LLO, while at the adjacent landing pad, a second LLV awaits servicing prior to its next mission. In the right foreground, increased numbers of government and industry personnel have taxed the capabilities of several previously landed habitat modules necessitating construction of an inflatable dome for added living room. The dome is covered by an outer layer of bagged regolith and an inner layer of hydrogenous material (e.g., plastic, water) to provide shielding against GCR and secondary neutron radiation. Lastly, nuclear reactors will be critical to providing a good return to investors in the LUNOX enterprise. They provide abundant power at low mass to support continuous operation of the teleoperated surface vehicles, production units and habitat modules even during the two-week lunar night. As production capacity increases, the LUNOX enterprise can expand its commercial operations to include metals processing (e.g., iron and titanium), power generation, maintenance and operations of surface-based LLVs and LLO propellant depots, and ultimately a lunar tourism industry.

\section{"REVOLUTIONARY PROPULSION THROUGH EVOLUTIONARY DEVELOPMENT"}

A variety of lunar transportation system concepts were examined by NASA 17 and the Synthesis Group 18 in the late 1980's and early 1990's. Most of these used liquid oxygen and hydrogen $\left(\mathrm{LOX} / \mathrm{LH}_{2}\right)$ chemical propulsion and were expendable or partially reusable at best. The reusable designs used a large aerobrake to return the LTV back to LEO while the LLV was expended in LLO. Concurrent with these studies, the individual benefits of extraterrestrial resources and NTR propulsion were also being examined. The importance of LUNOX for both reducing the direct expense of going to the Moon and increasing the viability of a "self-sufficient" long-term lunar base was highlighted by the Synthesis Group in its Space Resource Utilization architecture.18,19

During the same time period, NTR propulsion was examined by Lewis Research Center (LeRC) because of its high specific impulse (Isp -850. $1000 \mathrm{~s})$ and engine thrust levels ( 15-75 klbf). Analysis of a lunar NTR system 20 indicated a number of attractive mission benefits which included: (1) an "all propulsive" mission architecture; (2) full recoverability of both the NTRpowered LTV and its LLV payload at mission end (see Figure 4); and (3) a lower IMLEO than that of 


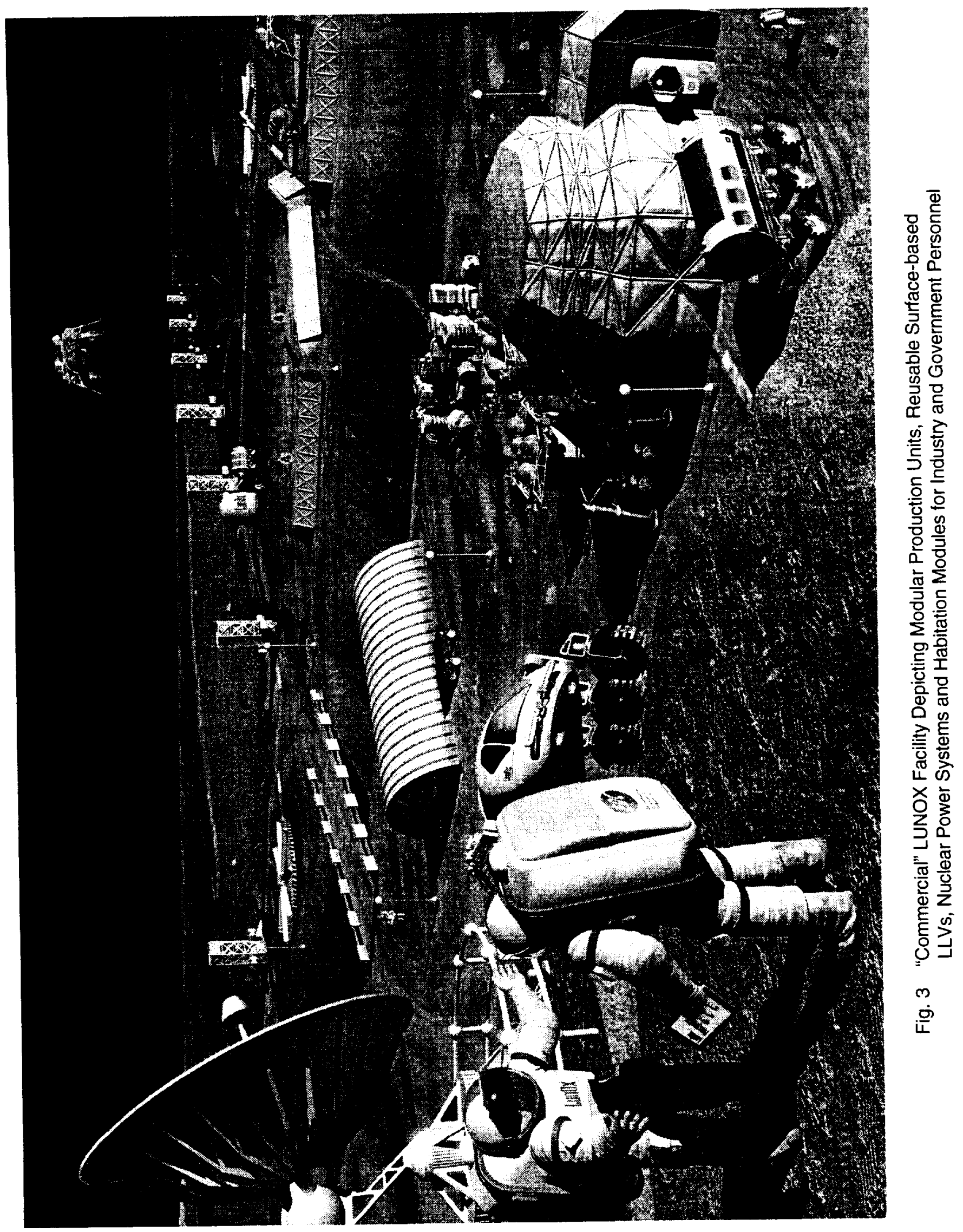


the partially reusable, aerobraked chemical system.

Reusability of the NTR system from the outset, however, required investing in a supporting LEO infrastructure--specifically a $\mathrm{LH}_{2}$ propellant depot or expendable tanker-- to refuel the vehicle for the next mission. The use of low density $\mathrm{LH}_{2}$ as reactor coolant and exhaust propellant also increased LTV size and necessitated large diameter $(\sim 10 \mathrm{~m})$ payload shrouds to launch vehicle components. To exploit the performance capability of the NTR, reduce vehicle size and capitalize on the availability of LUNOX at the Moon, an innovative propulsion concept was proposed by LeRC and Aerojet 21,22 which combines conventional $\mathrm{LH}_{2}$-cooled NTR and supersonic combustion ramjet (scramjet) technologies. Known as the LOX-augmented NTR (LANTR), it provides the basis for a "revolutionary" LTS architecture possessing a variety of engine, vehicle and mission benefits.

\section{LANTR: "THIS IS NOT YOUR FATHER'S NTR"}

The LANTR concept is a "trimodal" engine which can operate as a conventional $\mathrm{LH}_{2}$-cooled NTR, a bipropellant $\mathrm{LOX} / \mathrm{LH}_{2}$ engine and a power reactor. Its principal components include a nuclear fission reactor and nozzle to heat and expand propellant, hydrogen and oxygen feed systems and tankage, and a closed Brayton cycle system for electric power generation and engine "cooldown" assist. During LANTR operation, oxygen is injected into the large divergent section of the NTR nozzle which functions as an "afterburner" (see Figure 5). Here, it burns spontaneously with the reactorheated hydrogen emerging from the LANTR's sonic nozzle throat adding both mass and chemical energy to the rocket exhaust--essentially "scramjet propulsion in reverse."

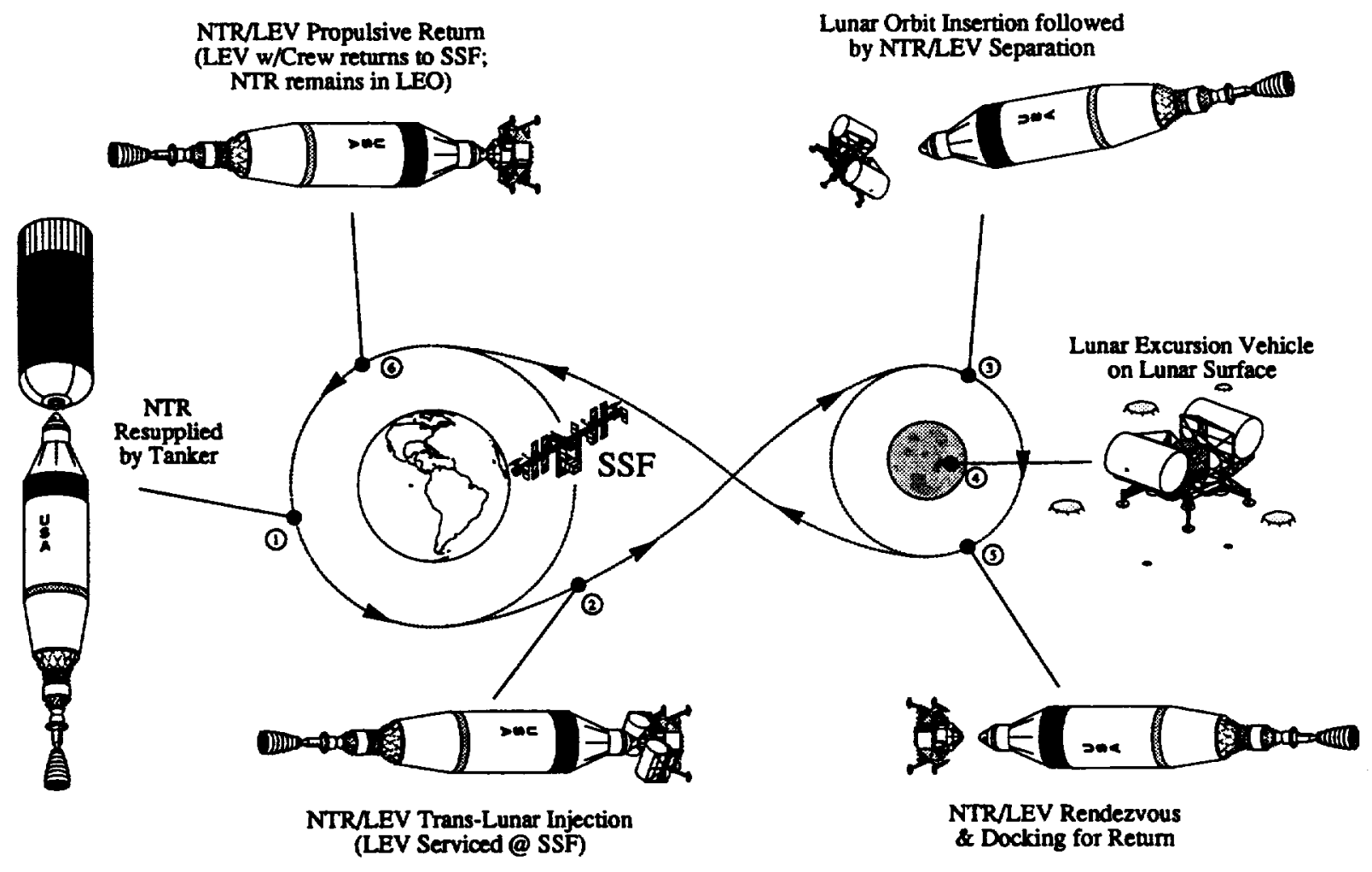

Fig. 4 Fully Reusable NTR Lunar Scenario 


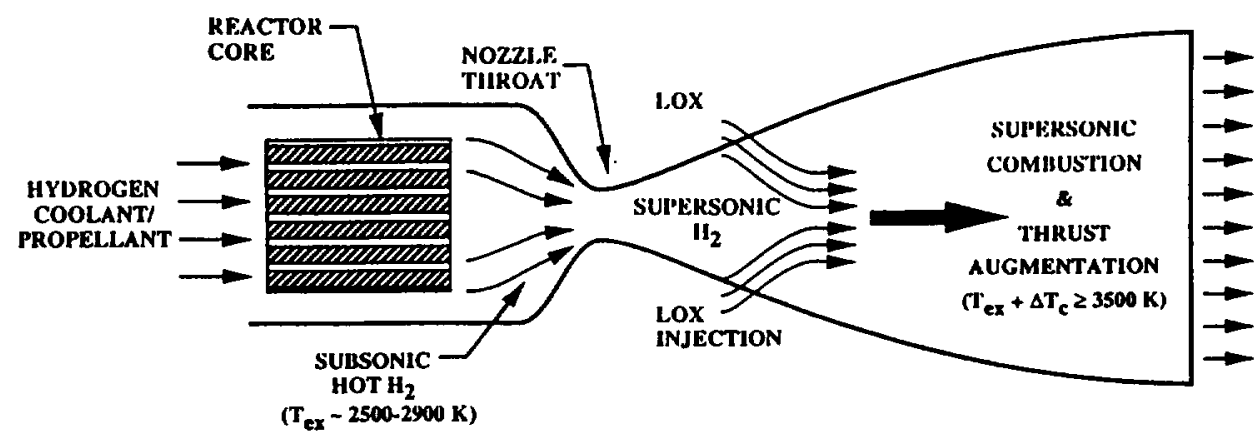

\begin{tabular}{|c|c|c|c|c|c|}
\hline \multirow[b]{2}{*}{$\begin{array}{l}\text { Life (hrs.) } \\
T_{c}\left({ }^{\circ} \mathrm{K}\right)\end{array}$} & \multicolumn{3}{|c|}{ Isp (sec) } & \multirow[b]{2}{*}{$\begin{array}{l}\text { Tankage } \\
\text { Fraction (\%) }\end{array}$} & \multirow[b]{2}{*}{$\begin{array}{l}\text { T/W } \\
\text { Ratio } \\
\end{array}$} \\
\hline & $\begin{array}{r}5 \\
2900\end{array}$ & $\begin{array}{c}10 \\
2800\end{array}$ & $\begin{array}{c}35 \\
2600\end{array}$ & & \\
\hline $\begin{array}{r}\mathrm{O} / \mathrm{H} \mathbf{M R}=\mathbf{0 . 0} \\
1.0 \\
3.0 \\
5.0 \\
7.0\end{array}$ & $\begin{array}{l}941 \\
772 \\
647 \\
576 \\
514\end{array}$ & $\begin{array}{l}925 \\
762 \\
642 \\
573 \\
512\end{array}$ & $\begin{array}{l}891 \\
741 \\
631 \\
566 \\
508\end{array}$ & $\begin{array}{r}14.0 \\
7.4 \\
4.1 \\
3.0 \\
2.5\end{array}$ & $\begin{array}{r}3.0^{\circ} \\
4.8 \\
8.2 \\
11.0 \\
13.1\end{array}$ \\
\hline
\end{tabular}

- For $15 \mathrm{klbf}$ LANTR with chamber pressure $=2000$ psia and $\epsilon=500$ to 1

Fig. 5 Schematic / Characteristics of LOX-Augmented NTR

Downstream nozzle injection in LANTR isolates the reactor core from oxygen's damaging effects and a "cascade" scramjet injector developed by Aerojet 21 helps control the oxygen addition and heat release within the nozzle to keep the flow supersonic. The cascade injector design also offers the potential for increased penetration, mixing and combustion of the oxygen injectant in the supersonic hydrogen flow while minimizing shock losses and nozzle wall "hot spots," thereby maximizing engine performance and life. The high reactor outlet pressure of LANTR ( $2000 \mathrm{psia})$ also enables high area ratio nozzles $(\varepsilon=500$ to 1$)$, important for combustion efficiency, at reasonable size and mass.

The LANTR has the potential to be an extremely versatile propulsion system. By varying the oxygen-to-hydrogen $(\mathrm{O} / \mathrm{H})$ mixture ratio (MR), the engine can operate over a wide range of thrust and Isp values (Figure. 5) while the reactor core produces a relatively constant power output. For example, as the MR varies from 0 to 7 , the engine thrust-to-weight ratio for a $15 \mathrm{klbf}$ NTR increases by $-440 \%$--from 3 to 13 --while the Isp decreases by only $-45 \%$--from 940 to 515 seconds. This thrust augmentation feature means that "big engine" performance can be obtained using smaller, more affordable, easier to test NTR engines. Shortened burn times also extend engine life and can improve "life cycle costs"--an important consideration in realizing "low cost access through space." Similarly, reactor preheating of hydrogen before oxygen injection and combustion results in higher Isp values than found in $\mathrm{LOX}_{\mathrm{LH}} \mathrm{H}_{2}$ chemical engines operating at the same mixture ratio $(\sim 100 \mathrm{~s}$ at MR $=6)$. Lastly, the increased use of high-density LOX in place of low-density $\mathrm{LH}_{2}$, and the ability to resupply or "reoxidize" LANTR vehicles with LUNOX in LLO prior to Earth return, are expected to significantly reduce vehicle size and mass while increasing delivered payload.

\section{A POSSIBLE STRATEGY FOR IMPLEMENTING LUNOX AND LANTR TECHNOLOGIES}

An "evolutionary" mission architecture employing lunar orbit rendezvous has been examined by LeRC which attempts to: (1) reduce "up-front" investment costs for in-space infrastructure; (2) eliminate the need for a new large heavy lift booster; (3) maximize surface payload per lunar 
landing mission; and (4) minimize LTS "recurring costs." To satisfy these objectives, a series of cargo and piloted missions are envisioned which use expendable "all $\mathrm{LH}_{2}$ " NTR systems initially to maximize the surface payload delivery while minimizing IMLEO requirements. The reduced IMLEO and size of the expendable vehicles also allows component delivery to LEO using a cargo version of the Space Shuttle (Shuttle C) or an "inline" Shuttle-derived launch vehicle (SDV), each with a lift capability of $\sim 66$ tons. The advantages of using Shuttle $C$ would be a low development cost and the ability to use much of the existing infrastructure (e.g., assembly buildings and launch pads) at the Kennedy Space Center.

The increased payload on each expendable NTR flight would be dedicated to delivering "modular" LUNOX production facilities. The intent here is to develop and use LUNOX to reoxidize LLVs and LTVs at the earliest possible opportunity and to then transition to a reusable LANTR architecture to improve "life cycle costs." Accrued government cost savings and industry profit from
LUNOX usage could then be reinvested gradually to develop additional "in-space" assets, such as LEO and LLO propellant depots, to support further reusability and eventually routine commuter flights to the Moon.

\section{LUNAR MISSION / TRANSPORTATION SYSTEM GROUND RULES AND ASSUMPTIONS}

The ground rules and assumptions for the evolutionary mission architecture examined in this study are summarized in Table 1. Provided are details on outbound and return payloads, parking orbits, mission velocity change $(\Delta V)$ requirements and duration, and Earth-to-orbit (ETO) launch vehicle characteristics. In addition to the three primary $\Delta V$ maneuvers (four for the NTR system) indicated, midcourse correction maneuvers are also performed using a storable, bipropellant RCS system. Table 2 . includes details on primary and auxiliary propulsion, cryogenic tankage, thermal protection and boiloff rates, and contingency factors used in this study.

Table 1. Reference Lunar Mission Ground Rules and Assumptions

$\begin{array}{lll}\text { - Payload Outbound: } & 9.9 \mathrm{t} & \text { LTV crew module } \\ & 0.8 \mathrm{t} & \text { Crew (4) and suits } \\ & 5.0-10.0 \mathrm{t} & \text { Lunar surface payload } \\ & 5.0 \mathrm{t} & \begin{array}{l}\text { LLV crew module } \\ \text { "Wet" LLV stage }\end{array} \\ & 35.7-46.0 \mathrm{t} & \text { "Wet } \\ & 9.9 \mathrm{t} & \text { LTV crew vehicle } \\ & 0.8 \mathrm{t} & \text { Crew (4) and suits } \\ & 0.5 \mathrm{t} & \text { Lunar samples }\end{array}$

$\begin{array}{lll}- \text { Parking Orbits: } & 407 \mathrm{~km} & \text { Circular (Earth Departure) } \\ & 300 \mathrm{~km} & \text { Circular (lunar arrival/departure) }\end{array}$

- Trans-lunar injection $\Delta \mathrm{V}$ assumed to be $3100 \mathrm{~m} / \mathrm{s}+\mathrm{g}$-losses

- Lunar orbit capture/trans-Earth injection $\Delta V$ 's assumed to be $915 \mathrm{~m} / \mathrm{s}$

- Earth return: Direct capsule entry

- Earth gravity assist disposal $\Delta V$ assumed to be $194 \mathrm{~m} / \mathrm{s}$ (for NTR missions)

- Mission duration: 54 days* (2 in LEO, 7 in transit, 45 days at Moon)

- ETO type/payload capability: Shuttle C or SDV / 66 t to $407 \mathrm{~km}$ circular

- LTV assembly scenario: 2 ETO launches with EOR\&D (IMLEO < 132 t)

"Chemical TLI and NTR "core" stages in LEO for 30 days prior to second ETO launch. 
Table 2. Lunar NTR / LANTR Transportation System Assumptions

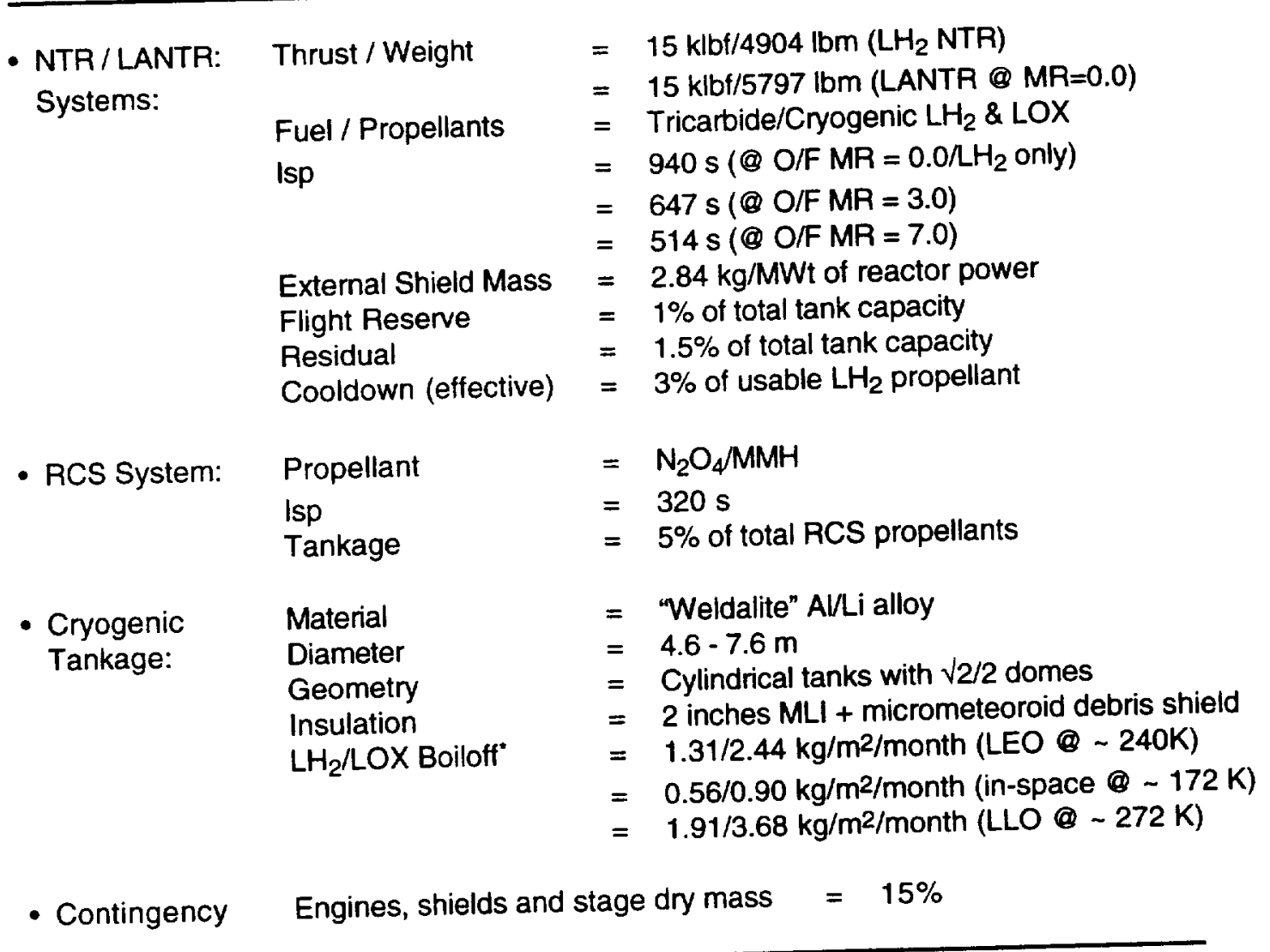

Assumes 3 x "Lockheed Eqn" heat flux estimates for MLI $\Delta t \sim 2$ inches

An aluminum-lithium alloy "Weldalite" $\left(F_{\text {tu }}=111\right.$ ksi, $\rho=0.0976 \mathrm{lbm} / \mathrm{in}^{3}=2700 \mathrm{~kg} / \mathrm{m}^{3}$ ), has been used in previous NASA contractor studies 23 of expendable, two-stage chemical LTV systems, and is also assumed here for construction of the lunar NTR's $\mathrm{LH}_{2}$ and LOX propellant tanks. Wall thicknesses for the $\mathrm{LH}_{2}$ tanks were calculated based on a 35 psi internal pressure and included hydrostatic loads using a " $3 \mathrm{~g}$ " load factor with a safety factor of 1.5. A 2.5 percent ullage factor was also assumed in this study. A 50 psi internal pressure was assumed for the LOX tanks resulting in wall thicknesses of $\sim 0.1$ inches.

A two-inch helium-purged, multilayer insulation (MLI) system (at 50 layers per inch) is assumed for thermal protection of the cryogenic tanks. This insulation thickness exceeds the "ground hold" thermal protection requirements for "wetlaunched" $\mathrm{LH}_{2}$ tanks which need a minimum of 1.5 inches of helium-purged insulation 24 . The installed density of the "2 inch MLI system" is $\sim 2.62 \mathrm{~kg} / \mathrm{m}^{2}$, and the resulting $\mathrm{LH}_{2}$ boiloff rate in LEO is $\sim 1.31$ $\mathrm{kg} / \mathrm{m}^{2} /$ month (based on an estimated heat flux of $\sim 0.22 \mathrm{~W} / \mathrm{m}^{2}$ at a LEO sink temperature of $\sim 240 \mathrm{~K}$ ). In lunar orbit, where the sink temperature and heat flux are estimated to be $-272 \mathrm{~K}$ and $0.32 \mathrm{~W} / \mathrm{m}^{2}$, respectively, the $\mathrm{LH}_{2}$ boiloff rate increases by $\sim 46 \%$ to $1.91 \mathrm{~kg} / \mathrm{m}^{2} /$ month. The corresponding boiloff rates for LOX are shown in Table 2. Finally, a $0.25 \mathrm{~mm}$ thick sheet of aluminum (corresponding to $-0.682 \mathrm{~kg} / \mathrm{m}^{2}$ ) is included in the total tank weight estimates to account for micrometeroid protection.

\section{CHEMICAL AND NTR COMPARISON RESULTS}

Figure 6 compares the relative size, mass and surface payloads for several piloted LTS options which include a $\mathrm{LOX} / \mathrm{LH}_{2}$ chemical system and 
several NTR systems operating without and with LOX-augmentation. Components for each piloted and cargo mission are delivered to LEO using two Shuttle C or SDV launches and assembled via a simple rendezvous and docking maneuver. The chemical LTS (Figure 6a) utilizes a "two stage" LTV. The first ETO flight delivers the trans-lunar injection (TLI) stage while the second ETO flight, launched 30 days later, delivers the lunar orbit insertion / trans-Earth injection (LOI / TEI) stage, crew module, and single stage LLV with its surface payload.

Following rendezvous and docking and 2 days of system checkout in LEO, the TLI stage uses its 5 RL10-derivative engines (with Isp 465 s) to inject the piloted LOI / TEI stage and lander elements on a translunar trajectory after which the TLI stage is jettisoned. Three RL 10-derivative engines are used in the LOI / TEI stage to capture into and depart from lunar orbit after completion of the 45-day landing mission. The $\sim 36 \mathrm{t} L L V$ uses five throttleable RL 10 s and can deliver $-5 \mathrm{t}$ of surface payload on the piloted missions. On cargo missions, the $5 \mathrm{t}$ crew module on the LLV can be removed and payloads on the order of $\sim 28 \mathrm{t}$ can be delivered on " 1 way" trips to the lunar surface.

The expendable "all $\mathrm{LH}_{2}$ " NTR vehicle is a "two tank" stage (Figure 6b). The first ETO flight delivers the "core" stage which is powered by two small $15 \mathrm{klbf}$ bimodal engines 21,22 each capable of generating $\sim 15 \mathrm{~kW}_{\mathrm{e}}$ of electrical power using a closed Brayton cycle power conversion unit (CBC/PCU). The bimodal NTR design considered here was developed jointly by Aerojet25, Babcock and Wilcox and Energopool in the Commonwealth of Independent States (CIS) under a contract to LeRC's Nuclear Propulsion Office. The CBC/PCU is enclosed within the conical extension of the stage thrust structure which also provides support for an $\sim 40 \mathrm{~m}^{2}$ heat pipe radiator required for the two engine system. Other elements on the NTR "core" stage include: (1) two external radiation shields for crew protection; (2) a $7.6 \mathrm{~m}$ diameter by $17.5 \mathrm{~m}$ long $\mathrm{LH}_{2}$ tank; (3) a forward cylindrical adaptor housing the RCS system, avionics and auxiliary power, and docking system; and (4) forward and aft cylindrical band skirts. The mass of the "dry" core stage, and its RCS and $\mathrm{LH}_{2}$ propellant loads are $16.0,0.4$, and $49.3 \mathrm{t}$, respectively, for a total mass at liftoff of $\sim 65.7 \mathrm{t}$. The "core" stage total length is a little over $24 \mathrm{~m}$, well within the $27.4 \mathrm{~m}$ payload length limit of the Shuttle C-Block 1 / SDV launch vehicle designs.

The second ETO launch delivers another $66 \mathrm{t}$ to LEO which consists of a second, smaller $\mathrm{LH}_{2}$ tank and its "conical" core stage adaptor, the piloted LTV crew module, and the LLV with its payload. The "in-line" $\mathrm{LH}_{2}$ tank is $4.6 \mathrm{~m}$ in diameter and $9.0 \mathrm{~m}$ long and has a $9 \mathrm{t} \mathrm{LH}_{2}$ propellant capacity. After rendezvous and docking, the $46 \mathrm{~m}$ long NTR LTV and its payload depart for the Moon. A "single burn" Earth departure scenario includes gravity losses of $\sim 392 \mathrm{~m} / \mathrm{s}$. The TLI burn duration is $\sim 47.5$ minutes and the total mission burn time for the two $15 \mathrm{klbf}$ NTRs is $\sim 61.4$ minutes.

Because of its high Isp ( $940 \mathrm{~s})$, the NTRpowered LTV can transport a larger $(\sim 44 \mathrm{t})$ piloted LLV to the Moon capable of landing $\sim 9$ t of surface payload--an $80 \%$ increase over the chemical system for the same IMLEO. The same LLV, minus the $5 \mathrm{t}$ crew module, can deliver $-34 \mathrm{t}$ of payload to the lunar surface on "1 way" cargo missions.

After lunar orbit rendezvous and docking of the piloted LLV with the LTV, and transfer of crew and lunar samples to the LTV crew module, the LLV is jettisoned and the NTR core stage performs a TEI burn to return to Earth. Following a 3.5 day transit, the LTV crew module separates for its ballistic reentry to Earth, while the NTR LTV performs a final small $(-194 \mathrm{~m} / \mathrm{s})$ Earth perigee burn which places the spent stage on a "long-term disposal" trajectory into heliocentric space. This same disposal scenario is repeated on cargo missions.

\section{Performance Impact of Introducing LUNOX and then LANTR Technologies}

The first significant step towards reducing space transportation costs is achieved when lunar outpost assets and LUNOX production levels become sufficient to support a lunar surface-based LLV. By not having to transport a "wet" LLV to LLO on each flight, the expendable NTR stage now has sufficient propellant capacity to operate in the "reuse mode" (Figure 6c) while transporting up to $\sim 9$ t of payload to LLO. An expendable, Shuttle Cclass propellant tanker would be used to refuel the stage with $\sim 58 \mathrm{t}$ of $\mathrm{LH}_{2}$ before each new mission. Also, with $\sim 19.1$ t of LUNOX required by the LLV for each round trip to and from LLO, LUNOX 

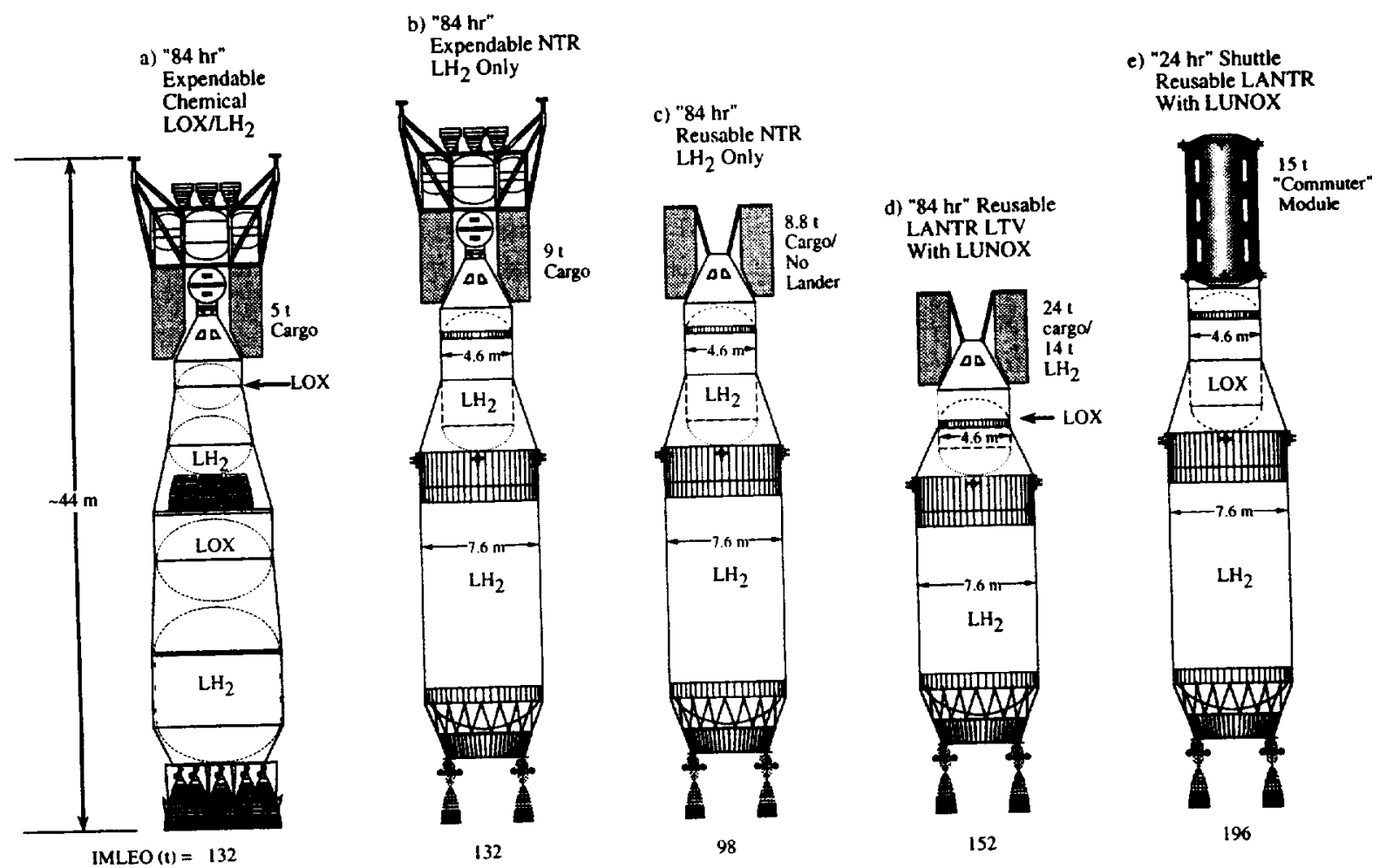

Fig. 6 Relative Size / Mass of Chemical and NTR Vehicles Without and With LOX Augmentation

production levels will depend on the number of cargo and piloted missions conducted annually.

Next, as LUNOX becomes available in LLO, the two $15 \mathrm{klbt}$ NTRs would be outfitted with a LOX propellant feed system and afterburner nozzles for bipropellant operation. Transition to a "LANTRbased" lunar architecture now begins with smaller, reusable LTVs (Figure $6 \mathrm{~d}$ ) delivering $\sim 38 \mathrm{t}$ of cargo and "Earth-supplied" propellants to LLO on each flight ( $>400 \%$ payload increase). Surface-based LLVs would be used to transport crew and cargo to the Moon. They would also deliver LUNOX to LLO to "reoxidize" the LANTR LTV and then return to the Moon with "Earth-supplied" $\mathrm{LH}_{2}$ for future use in LLVs and LUNOX production facilities.

In transitioning from an expendable to reusable mission architecture, the LLV loses some of its cargo delivery capability. This is due to the fact that the lander's tankage and propellant load $(-22.3 \mathrm{t}$ of $\mathrm{LOX} / \mathrm{LH}_{2}$ at $M R=6$ ) was sized to deliver $\sim 9 \mathrm{t}$ of surface payload on the initial expendable piloted missions. When the LLV (which has a "dry" mass of $11.4 \mathrm{t}$ including its $5 \mathrm{t}$ crew cab) operates from the lunar outpost, $-11.5 \mathrm{t}$ of propellant is used in ascending to LLO for rendezvous with the LTV. This estimate assumes an ascent $\Delta V$ of $-1900 \mathrm{~m} / \mathrm{s}$ and an Isp of $\sim 465 \mathrm{~s}$ for the LLV. To land $\sim 20.5 \mathrm{t}$ of cargo and $4 \mathrm{crew}$ on the lunar surface requires $-18.2 \mathrm{t}$ of propellant assuming a descent $\Delta \mathrm{V}$ of $-2000 \mathrm{~m} / \mathrm{s}$. The $10.8 \mathrm{t}$ of $\mathrm{LOX} / \mathrm{LH}_{2}$ propellant remaining in the LLV after ascent is therefore inadequate to transport this much cargo.

In the mission strategy we adopt here, the LANTR LTV doubles as a "tanker" vehicle and is loaded with additional propellant that is transferred to the LLV after rendezvous. This "topping off" of the LLV's tanks with $-7.4 \mathrm{t}$ of $\mathrm{LOX} / \mathrm{LH}_{2}$ propellant allows the crew and its entire cargo shipment to be delivered to the surface on one round trip LLV mission. The reusable LTV shown in Figure $6 \mathrm{~d}$ operates at a MR $=3$ (Isp $\sim 647 \mathrm{~s}$ ) both outbound and inbound, refuels with $-21.2 \mathrm{t}$ of LUNOX for Earth return, and is a smaller overall vehicle than its expendable "all $\mathrm{LH}_{2}$ " counterpart, even with its increased performance. The oxygen tank holds $-62 \mathrm{t}$ of LOX of which $\sim 6.4 \mathrm{t}$ is used for "topping off" the LLV and the remainder for the LTV's TLI 
and LOI maneuvers. The $\mathrm{LH}_{2}$ tank is $7.6 \mathrm{~m}$ in diameter, $15 \mathrm{~m}$ in length and holds $\sim 39 \mathrm{t}$ of $\mathrm{LH}_{2}$. Of this amount $\sim 11 \mathrm{t}$ is cargo. Two autonomous LLV "tanker" flights (see Figure 3 ), each supplying $\sim 10.6 \mathrm{t}$ of LUNOX to the orbiting LANTR LTV, return to the Moon with $\sim 10$ t of $\mathrm{LH}_{2}$ necessary to support the three LLV flights required for each subsequent LTV mission. With time, the deployment of a propellant depot in LLO will eliminate the need for LOX transport by the LTV. This will increase the LTV's delivery capability of cargo and $\mathrm{LH}_{2}$ propellant to $\sim 24 \mathrm{t}$ and $14 \mathrm{t}$, respectively (see Figure 6d).

Compared to monopropellant NTRs, the LANTR engines are $-5 \%$ longer (an expansion ratio of 500 to 1 is used for improved LOX combustion efficiency) and $-6 \%$ heavier (attributed to the larger nozzle and the addition of the LOX propellant feed system). However, at a $M R=3$, the thrust output $(F)$ from the two $15 \mathrm{klbf} \mathrm{LH}_{2}$ cooled NTRs is increased by $\sim 275 \%$ to $\sim 82.5 \mathrm{klbf}$. This augmented thrust level significantly reduces the TLI burn duration and gravity losses to $\sim 17.2$ minutes and $\sim 72 \mathrm{~m} / \mathrm{s}$, respectively, compared to 47.5 minutes and $392 \mathrm{~m} / \mathrm{s}$ for the expendable "all $\mathrm{LH}_{2}$ " $30 \mathrm{klbf}$ NTR system. Total mission burn time is also cut in half to $\sim 28.9$ minutes compared to -61.4 minutes for the expendable system. Also, because the LANTR engine's fuel lifetime is $\sim 5$ hours at a hydrogen exhaust temperature of $2900 \mathrm{~K}$ (see Figure 5), the LANTR system can perform $\sim 10$ round trip lunar missions before being replaced thereby reducing overall LTS recurring costs.

The reusable LANTR LTV has an IMLEO of $\sim 151.8 \mathrm{t}$ which includes the $17.9 \mathrm{t}$ "dry" stage, a 10.7 t piloted LTV crew module, $20.5 \mathrm{t}$ of nonpropellant cargo, and RCS, $\mathrm{LH}_{2}$, and $\mathrm{LOX}$ propellant loads of $\sim 1.7,39$ and $62 t$, respectively. During initial deployment, the entire LANTR LTV, including its $\mathrm{RCS}$ and $\mathrm{LH}_{2}$ propellant loads, can be launched on a single Shuttle C or SDV. The LOX tank would require on-orbit filling from an expendable tanker or propellant depot. For subsequent piloted missions, the total mass needed to outfit and refuel the LTV stage is $\sim 123.2 \mathrm{t}$ which again can be delivered using two $66 \mathrm{t}$-class Shuttle C /SDV launch vehicles.

Approximately $76.5 \mathrm{t}$ of LUNOX ( $21.2 \mathrm{t}$ for LTV return, $\sim 19.1 \mathrm{t}$ for the piloted $\mathrm{LLV}$, and $\sim 36.2 \mathrm{t}$ for the two tanker LLVs) must be produced to support each reusable LTV mission. At a low LUNOX production capacity $(\sim 12$ to 24 t/year), small automated LUNOX units with teleoperated mining equipment would be delivered to LLO by monopropellant NTR and later LANTR systems, and then transported to the lunar surface using "onboard" chemical propulsion systems 26 . As capacity increases to hundreds of tons per year and more, surface assembly of larger production units will be required to avoid the mass penalties associated with delivering increased numbers of low-rate production plants. 7

\section{A TYPICAL "COMMUTER TRIP" TO THE MOON}

With LUNOX production underway and a reusable LANTR-based LTS in service, initial lunar outposts will grow into permanent settlements staffed by visiting scientists and engineers representing both government and private commercial ventures (see Figure 3). Eventually, frequent flights to the Moon of shortened duration could also become commonplace. The LANTR concept can enable a rapid "commuter" shuttle capable of 24-hour "1-way" trip times to and from the Moon, about what it now takes to travel from Washington, D.C. to Sydney, Australia. Shortening transit times will require significant increases in both the outbound and inbound $\Delta \mathrm{V}$ budgets (see Figure 7) and necessitate multiple spacecraft engines for improved reliability and increased passenger safety. In the Apollo program, a 3.5 day trip to the Moon required an outbound $\Delta V$ of $\sim 4.1$ $\mathrm{km} / \mathrm{s}$. For the 24 hour "1-way" trip times examined here, the required $\Delta \mathrm{V}$ budget is $-6.9 \mathrm{~km} / \mathrm{s}$ !

The LANTR-based "commuter" shuttle, illustrated in Figure 8 and on our cover page, is a modified version of the "all $\mathrm{LH}_{2}$ " NTR vehicle and is capable of delivering a $15 \mathrm{t}$ passenger module to the Moon in a single day. In addition to utilizing LANTR engines, the other principal vehicle modification is the use of LOX instead of $\mathrm{LH}_{2}$ in the small "in-line" propellant tank located ahead of the $\mathrm{LH}_{2}$ "core" stage (Figure 6e). In our reference commuter flight, we assume the LANTR shuttle uses only "Earth-supplied" $\mathrm{LH}_{2}$ in traveling to and from the Moon with "Earth-supplied" LOX and LUNOX used only on the outbound and inbound mission legs, respectively. To extend the service lifetime of the lunar shuttle, the LANTR engines are also operated at a reduced hydrogen exhaust 


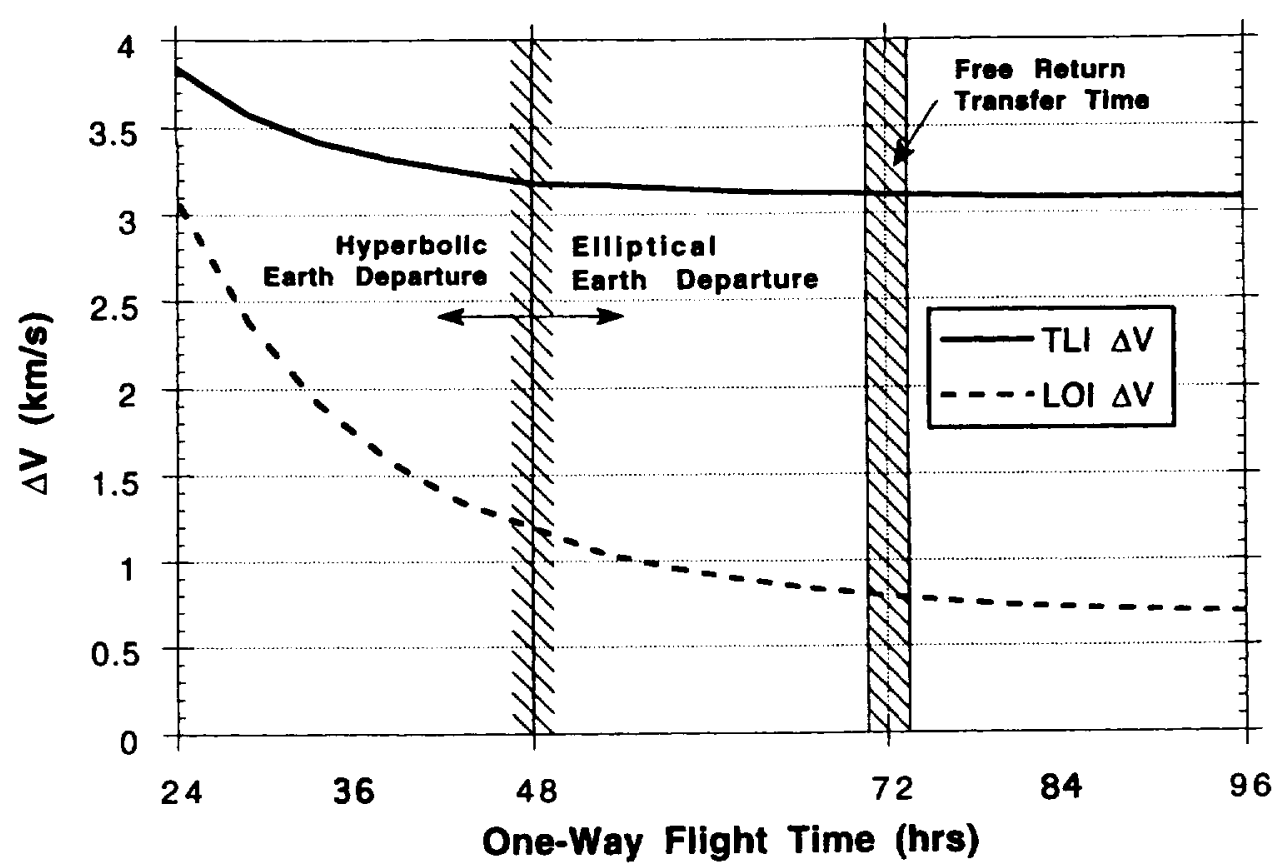

Fig. 7 TLI and LOI $\Delta V$ Variation with "1 way" Flight Time (300 km Lunar Orbit)

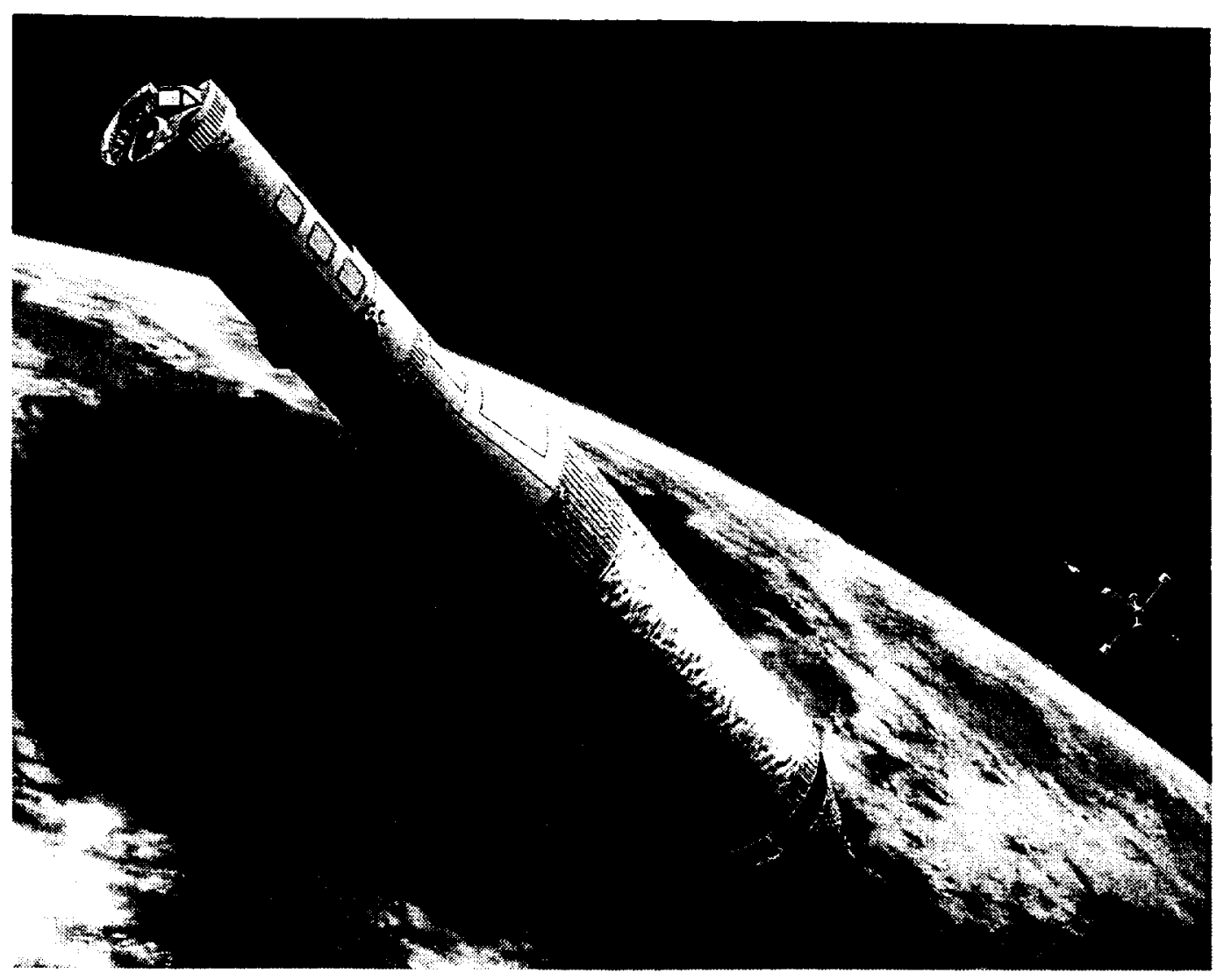

Fig. 8 A LANTR-powered Transfer Stage Leaves Earth Orbit Carrying a Passenger Transport Module on a "24 Hour" Trip to the Moon 
temperature of $\sim 2600 \mathrm{~K}$ which increases fuel lifetime to $\sim 34.5$ hours compared to $\sim 5$ hours at $2900 \mathrm{~K}$ (see Figure 5).

During the transit out to the Moon, the twin LANTR engines operate at a $M R=4(F \sim 100 \mathrm{klbf}$ and Isp 595 s) while on the return trip to Earth, a $M R=6(F \sim 126 \mathrm{klbf}$ and Isp 537 s) is used. These conditions provide both near optimum performance levels and vehicle components of sufficient size to allow deployment using 2 Shuttle $C$ flights. The initial and resupply propellant needs of the "24 hour" LANTR shuttle are provided by a LEO propellant depot assumed to be in existence during this period. The commuter shuttle's LOX tank is $4.6 \mathrm{~m}$ in diameter, $-7.5 \mathrm{~m}$ long and holds $-112 t$ of Earth-supplied LOX for the outbound lunar flight. It is resupplied in LLO with $\sim 94 \mathrm{t}$ of LUNOX for the 24 hour trip back to Earth. The LANTR shuttle uses the same size $\mathrm{LH}_{2}$ tank as the expendable NTR system to exploit hardware commonality and reduce development costs. It carries $\sim 46 \mathrm{t}$ of $\mathrm{LH}_{2}$ required for the round trip mission.

The "24 hour" LANTR shuttle has an IMLEO of -195.6 t that includes the $21.3 \mathrm{t}$ "dry" vehicle, the $15 \mathrm{t}$ passenger module, and RCS, $\mathrm{LH}_{2}$ and $\mathrm{LOX}$ propellant loads of $\sim 1.5,45.5$ and $112.3 \mathrm{t}$, respectively. Total engine burn time for the " 24 hour" mission is just under 47 minutes with the longest single burn being the TLI maneuver at -21.2 minutes. With a 34.5 hour fuel lifetime, a typical LANTR shuttle could perform 44 missions. Assuming a four ship fleet with weekly trips to the Moon, each LANTR shuttle would make 13 lunar flights per year resulting in a service life of -3.3 years. Near the end of life, the shuttle's $\mathrm{LH}_{2}$ core stage could be used to deliver cargo to the Moon or Mars before being disposed of in heliocentric space. The 15 t passenger transport module is $-4.6 \mathrm{~m}$ in diameter and $\sim 8 \mathrm{~m}$ long, and can be delivered to orbit using the current Space Shuttle or the next generation RLV.

To support weekly commuter flights to the Moon will require annual LUNOX production levels of $\sim 11,000 \mathrm{t} / \mathrm{yr}$ (see Table 3). Approximately $4900 \mathrm{t}$ are used by the LANTR shuttles and just over $6000 \mathrm{t}$ by four second-generation "Sikorsky-style" LUNOX tanker LLVs which fly one supply mission to the LLO propellant depot each week over the course of a year. Each tanker LLV has a "dry" mass of $\sim 10.9 \mathrm{t}$ and carries $\sim 33.6 \mathrm{t}$ of $\mathrm{LOX} / \mathrm{LH}_{2}$ propellant in addition to the $\sim 30 \mathrm{t}$ "mobile" tanker vehicle with its $25 \mathrm{t}$ LUNOX payload.

A preliminary assessment of plant mass, power level, regolith throughput, and required mining area has been made assuming a LUNOX operation employing eleven modular units each with a production capacity of $1000 \mathrm{t} / \mathrm{yr}$. Table 4 compares characteristics for two LUNOX plants--one based on hydrogen reduction of ilmenite 7 and the other on "iron-rich" volcanic glass. The advantages of using volcanic glass feedstock are apparent and indicate mass and power requirements $\sim 68 \%$ and $80 \%$ that of an ilmenite reduction plant using a soil feedstock. The $4 \% \mathrm{O}_{2}$ yield using volcanic glass beads ("orange soil") also translates into more than an order of magnitude reduction in the amount of mined regolith. To produce $\sim 11,000 \mathrm{t}$ of LUNOX annually will require a regolith throughput of $\sim 2.75 \times 10^{5} \mathrm{t} / \mathrm{yr}$ and a soil mining rate of $-90 \mathrm{t}$ per hour assuming a $35 \%$ mining duty cycle (i.e.,70\% of the available lunar daylight hours). While this number is large, it is modest compared to terrestrial coal and proposed lunar helium-3 mining activities. For example, with a single $1000 \mathrm{MW}_{\mathrm{e}}$ "coal-fired" power plant consuming about sixty 100 ton train cars of coal per day, the annual U.S. production rate for coal exceeds 500 million tons! Similarly, proposals for mining helium-3 on the Moon 27 to support a future fusion-based power economy in the U.S. would require the processing of $\sim 2.8$ billion tons of regolith to obtain the $20 \mathrm{t}$ of $\mathrm{He}^{3}$ needed annually (see Table 4).

Because of the abundance of oxygen in the lunar regolith, the scale of the mining operation to support routine commuter flights to the Moon is not unrealistic. Figure 9 illustrates the areal extent and potential LUNOX yield from our candidate mining site at the southeastern edge of Mare Serenitatis. Assuming an area of $\sim 2000 \mathrm{~km}^{2}$, a mining depth of $\sim 5 \mathrm{~m}$, a soil density representative of the Apollo 17 orange soil $\left(\rho \sim 1.8 \mathrm{t} / \mathrm{m}^{3}\right)$, and a MMR of 25 to 1, a LUNOX yield of $\sim 700$ million tons is possible. Also illustrated in Figure 9 are the required mining areas needed to support weekly, as well as, daily commuter flights to the Moon. Even at the higher production rate of $\sim 77,000 \mathrm{t} / \mathrm{yr}$, there are sufficient LUNOX resources at this one site to support daily lunar commutes for the next 9000 years and many more sites of "iron-rich" volcanic glass have been identified. 28 
Table 3. LUNOX Requirements for " 24 Hour" Commuter Flights to the Moon

24 Hour "1-way" Transits (15 t/20 Passenger Transport Module):

LTV: (94.0 t LUNOX / mission $\left.{ }^{*}\right) \times 52$ weeks / year $\quad=4888 \mathrm{t} /$ year

LLV: $\left(28.8\right.$ t LUNOX / flight $\left.{ }^{+}\right) \times(1$ flight / LLV / week) x 4 LLVs $\times 52$ weeks / year $=5990 t /$ year

Total LUNOX Rate $=10878 \mathrm{t} /$ year

"Assumes LUNOX Usage on "Moon-to-Earth"Transit only

+ Assumes LLV Transports $\sim 25$ t of LUNOX to LLO and Returns to Lunar Surface with Empty $5 \mathrm{t}$ "Mobile" LUNOX Tanker Vehicle

Table 4. Comparison of Different Lunar Mining Concepts --Plant Mass, Power and Regolith Throughput--

- Hydrogen Reduction of llmenite": (LUNOX Production @ 1000 t/year)

- Plant Mass (Mining, Beneficiation, Processing \& Power)

- Power Requirements (Mining, Beneficiation \&Processing)

$=244 \mathrm{t}$

$=3.0 \mathrm{MWe}$

- Regolith Throughput ( assumes soil feedstock 17.5 wt\% ilmenite \& mining mass ratio (MMR) of $327 \mathrm{t}$ of soil per ton of LUNOX) $=2.3 \times 10^{5} \mathrm{t} / \mathrm{yr}$

- Hydrogen Reduction of "Iron-rich" Volcanic Glass: (LUNOX Production @ $1000 \mathrm{t} / \mathrm{yr}$ )

- Plant Mass (Mining, "limited" Beneficiation, Processing \& Power) $=167 \mathrm{t}$

- Power Requirements (Mining, "limited" Beneficiation \& Processing) =2.4 MWe

- Regolith Throughput ("limited" beneficiation, direct processing of "iron-rich" volcanic glass ("orange soil") with $4 \% \mathrm{O}_{2}$ yield \& MMR = 25 to 1) $=2.5 \times 10^{4}$ t/yr

- Lunar Helium-3 Extraction: (5000 kg (5 t) He $3 /$ year)

- Mobile Miners (150 miners required each weighing $18 \mathrm{t}$ / each miner produces $33 \mathrm{~kg} \mathrm{He}$ per year)

$=2700 t$

- Power Requirements (200 kW direct solar power/miner)

$=30.0 \mathrm{MW}$

- Regolith Throughput (processing \& capture of Solar Wind Implanted (SWI) volatiles occurs aboard the miner)

$=7.1 \times 10^{8} \mathrm{t} / \mathrm{yr}$ 


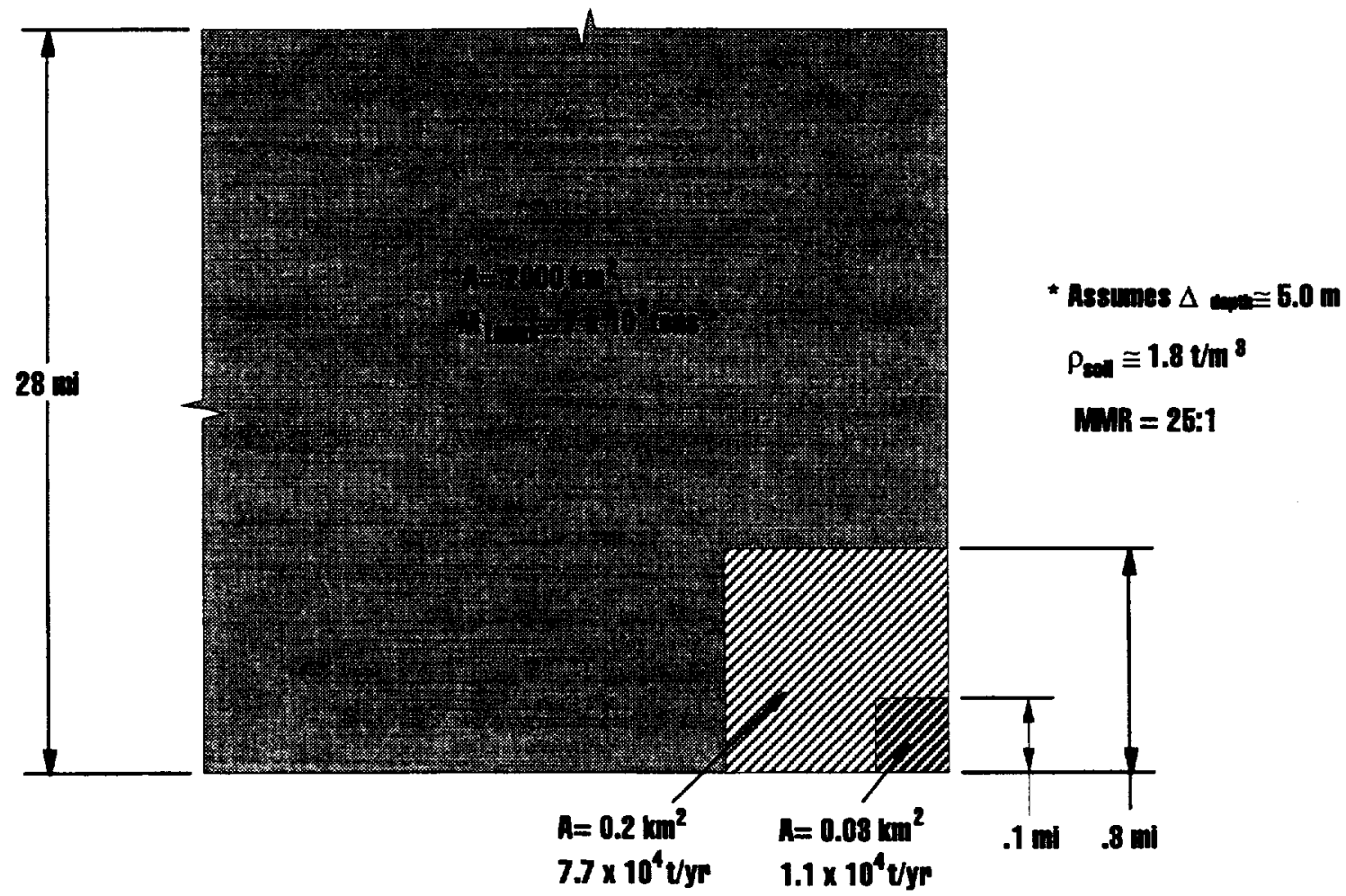

Fig. 9 Required Mining Areas and LUNOX Production Rates to Support Routine Commuter Flights to the Moon

How might a typical "commuter" trip to the Moon proceed? A possible scenario might start with passengers boarding a future transatmospheric shuttle or a passenger version of the RLV for a flight to the International Space Station (ISS). There they would enter a "passenger transport module" (PTM) containing its own life support, power, instrumentation and control, and auxiliary propulsion systems. The PTM provides the "brains" for the LANTR-powered shuttle and is home to the 18 passengers and 2 crew members while enroute to the Moon. After departing from the ISS, the PTM docks with a fully fueled LANTR shuttle awaiting it a safe distance away. At the appropriate moment, the LANTR engines are powered up and the shuttle climbs rapidly away from Earth (Figure 8). Acceleration levels experienced by the passengers during Earth departure range from $-0.23 \mathrm{~g}$ to $\sim 0.46 \mathrm{~g}$ near the end of the TLI burn.

Following a 24 hour trip to the Moon, the LANTR shuttle arrives in LLO where the PTM detaches and docks with a waiting LLV (Figure 10). A commercial propellant depot provides a convenient staging point for LLO operations supplying the LANTR shuttle with LUNOX for Earth return and the "Sikorsky-style" LLV with Earthsupplied $\mathrm{LH}_{2}$ needed to deliver the PTM to the lunar surface. From here the PTM is lowered to a "flat-bed" surface vehicle and electronically engaged providing it with surface mobility (see Figure 11). The PTM then transports itself to the lunar base airlock for docking and passenger unloading (shown in lower right foreground of Figure 3). The scenario is reversed on the return trip to Earth where peak acceleration levels reach $\sim 1.2 \mathrm{~g}$ at the end of the Earth orbit capture burn.

\section{CONCLUSION}

The revolutionary performance capability discussed in this paper is the result of combining two, relatively near term, "high leverage" technologies. Together, LANTR propulsion and LUNOX have an "effective Isp" of $\sim 1500$ to $2000 \mathrm{~s}$ which is equivalent to that predicted for advanced "gas core" NTR systems. Using chemical propulsion, a fully reusable "advanced technology" system (propellant mass fraction of 0.88 and Isp of 


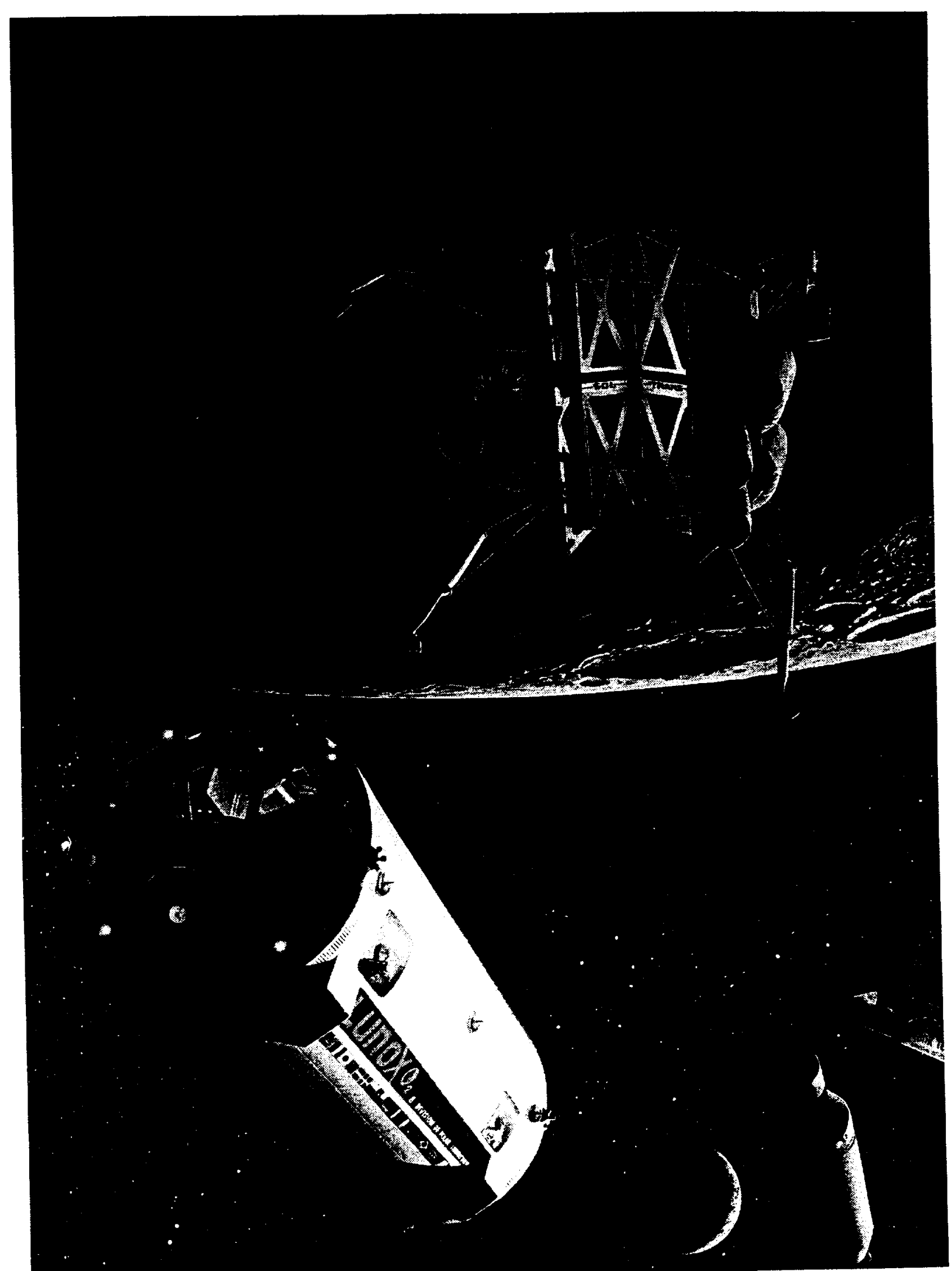

Fig. 10 A Surface-based LLV Prepares to Dock with a Passenger Transport Module Delivered to Lunar Orbit by the LANTR-powered Transfer Stage 


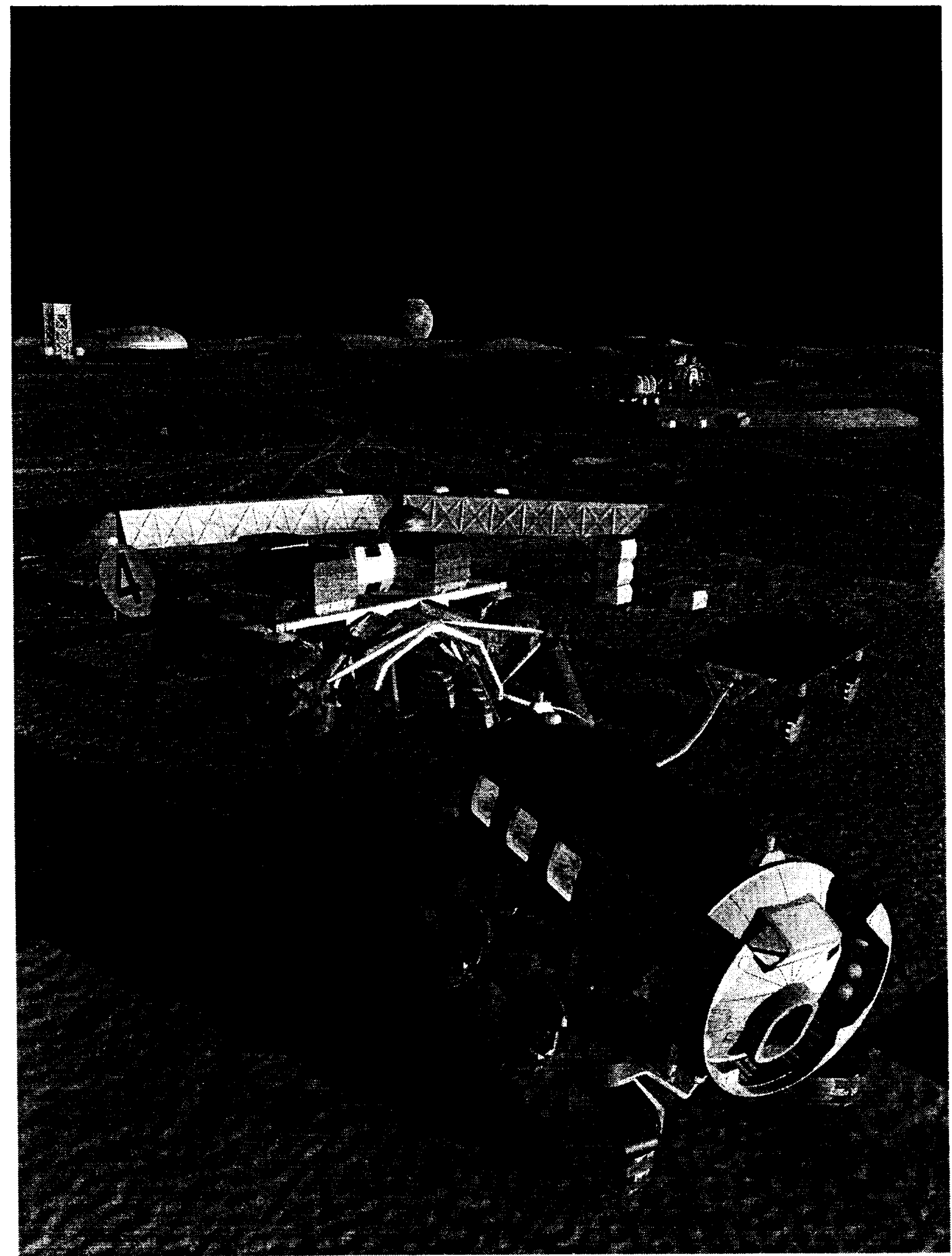

Fig. 11 After Landing on the Lunar Surface, the Passenger Transport Module Departs for the Lunar Settlement Aboard a "Flatbed" Surface Transport 
$\sim 480 \mathrm{~s}$ ), would require IMLEO and LUNOX production levels 2 to 3 times higher than LANTR to perform the same commuter flight.

In addition to enabling commuter flights to the Moon, the LANTR concept is expected to dramatically improve space transportation performance wherever extraterrestrial sources of $\mathrm{LOX}$ and $\mathrm{LH}_{2}$ can be acquired such as the Martian system, mainbelt asteroids and the Galilean satellites Europa, Ganymede, and Callisto. In the future, reusable biconic-shaped LANTR-powered ascent/descent vehicles, operating from specially prepared landing sites on Mars, could be used to transport modular payload elements to the surface while resupplying orbiting transfer vehicles with propellants needed to reach refueling depots in the asteroid belt. From there, the LANTR-powered transfer vehicles could continue on to the "water rich" moons of the Jovian system, providing a reliable foundation for the development and eventual human settlement of the Solar System.

This December marks the 25th anniversary of the Apollo 17 mission to Taurus-Littrow and unfortunately, the termination of both the Apollo and NERVA nuclear rocket programs. In the notso-distant future, the technological progeny from these two historic programs-- LUNOX and LANTR-could provide the traveling public the type of revolutionary space transportation portrayed in 2001:A Space Odyssey and in Clarke's novel29 by the same name thereby allowing future Dr. Floyds the opportunity to make "...utterly without incident and in little more than one day, the incredible journey of which men had dreamed for two thousand years...." a routine flight to the Moon.

\section{ACKNOWLEDGEMENTS}

The authors wish to express thanks to their respective organizations for support during the course of this study. One of the authors, Dr. Stanley Borowski, would also like to express his gratitude to the following individuals for their contributions to this paper: Kriss Kennedy (NASA IJSC) for his preliminary assessment of the PTM mass; noted space artist, Pat Rawlings (SAIC) for artwork depicted on the paper's cover and in Figures 3, 8, 10 and 11; and Melissa McGuire (Analex) for her assistance in the preparation of tables and figures used in this paper.

\section{REFERENCES}

1. 2001: A Space Odyssey, produced and directed by $S$. Kubrick, screenplay by $S$. Kubrick and A. C. Clarke, a Metro-Goldwyn-Mayer (MGM) film released 1968.

2. D. A. Brown, "International Space Station Faces Further Delays, Controversary," Launchspace, (June/July 1997), pp.30-34.

3. M. H. Kaplan, "The Reusable Launch Vehicle: Is the Stage Set?," Launchspace, (March 1997), pp.26-30.

4. The Strategic Plan--NASA's Enterprise for the Human Exploration and Development of Space, National Aeronautics and Space Administration, (January 1996).

5. T. S. Sullivan and D. S. McKay, Using Space Resources, NASA Johnson Space Center (1991).

6. L. A. Taylor and W. D. Carrier III, "The Feasibility of Processes for the Production of Oxygen on the Moon," in Engineering. Construction \& Operations in Space III, New York, 1992, pp.752-762.

7. E. L. Christiansen, et al., "Conceptual Design of a Lunar Oxygen Pilot Plant," Eagle Engineering Report No. 88-182, Eagle Engineering, Inc., Houston, Texas (July1, 1988).

8. W. R. Stump, et al., "Support to Extraterrestrial Propellant Leveraging Trade Study," Eagle Engineering Report No. 89-251, Eagle Engineering, Inc., Houston, Texas (August 15,1989).

9. C. C. Allen, R. V. Morris, and D. S. McKay, "Experimental Reduction of Lunar Mare Soil and Volcanic Glass," Journal of Geophysical Research, $\underline{99}, 23,173$ (November 1994).

10. C. C. Allen and D. S. McKay, "Lunar Oxygen Production--Ground Truth and Remote Sensing," AlAA-95-2792, American Institute of Aeronautics and Astronautics (July 1995).

11. C. C. Allen, "Prospecting for Oxygen on the Moon," Ad Astra, (Nov./Dec. 1996), pp.34-39.

12. W. H. Gregory, "Apollo 17 Photos Confirm Color of Soil Discovered at 'Shorty'," Aviation 
Week \& Space Technology, (January 1, 1973), p.15.

13. W. H. Gregory, "Orange Soil Could Revive Lunar Projects," Aviation Week \& Space Technology, (January 1, 1973), pp.41-44.

14. M. B. Duke and M. Treadwell, "A Proposal for Risk Sharing in the Development of a Lunar Oxygen Plant," in Engineering. Construction, and Operations in Space 11: Vol. 1, New Mexico, 1990, pp.41-49.

15. T. F. Rogers, "The People Payload: Does the U. S. Space Transportation Industry Take Space Tourism Seriously?," Ad Astra, (March/April 1995), pp.36-39.

16. L. David, "NASA Begins Space Tourism Enterprise Assessment--Findings Could Influence the Future of X-33," Space News, (September 18$24,1995)$.

17. C. C. Priest and G. R. Woodcock, "Space Transportation Systems Supporting a Lunar Base," AlAA-90-0422, American Institute of Aeronautics and Astronautics (January 1990).

18. America at the Threshold--America's Space Exploration Initiative, Report of the Synthesis Group, Available from the Superintendent of Documents, U.S. Government Printing Office, Washington, DC 20402 (May 1991).

19. "Analysis of the Synthesis Group's Space Resource Utilization Architecture," ExPO Document XE-92-004 (February 1992).

20. S. K. Borowski, "The Rationale/Benefits of Nuclear Thermal Rocket Propulsion for NASA's Lunar Space Transportation System," AIAA-912052. American Institute of Aeronautics and Astronautics (June 1991).

21. S. K. Borowski et al., "A Revolutionary Lunar Space Transportation System Architecture Using Extraterrestrial LOX-Augmented NTR Propulsion," AIAA-94-3343, American Institute of Aeronautics and Astronautics (June 1994).

22. S.K. Borowski, D. W. Culver, and M. J. Bulman, "Human Exploration and Settlement of the Moon Using LUNOX-Augmented NTR Propulsion," in
Proc. 12th Symposium on Space Nuclear Power and Propulșion, AIP Conf. Proc. No. 324, January 1995, Vol. 1, pp.409-420.

23. "Space Transfer Vehicle Concepts and Requirements Study," Martin Marietta , Denver, Colorado, Marshall Space Flight Center Space Transportation Week \#5 Report, December 4, 1991.

24. R. H. Knoll, R. J. Stochl, and R. Sanabria, "A Review of Candidate Multilayer Insulation Systems for Potential Use on Wet-Launched $\mathrm{LH}_{2}$ Tankage for the Space Exploration Initiative Lunar Mission," AlAA-91-2176, American Institute of Aeronautics and Astronautics (June 1991).

25. D. W. Culver, V. Kolganov, and R. Rochow, "Low Thrust, Deep Throttling, US/CIS Integrated NTRE," 11th Symposium on Space Nuclear Power Systems, Albuquerque, New Mexico, (January 913, 1994).

26. B. K. Joosten and L. A. Guerra. "Early Lunar Resource Utilization:A Key to Human Exploration," AlAA-93-4784, American Institute of Aeronautics and Astronautics (September 1993).

27. I. V. Sviatoslavsky, "Processes and Energy Costs for Mining Lunar Helium-3," in Workshop Proc. on Lunar Helium-3 and Fusion Power, NASA CP-10018 (1988), pp.129-146.

28. B. R. Hawke, C. R. Coombs, and B. Clark, "Pyroclastic Deposits as Sites for Lunar Bases," in Engineering. Construction, and Operations in Space Il: Vol.1, New Mexico, 1990, pp.78-87.

29. A. C. Clarke, 2001: A Space Odyssey, based on a screenplay by S. Kubrick and A. C. Clarke, a Signet Book, published by The New American Library, Inc., (July 1968), p.61. 


\section{.}




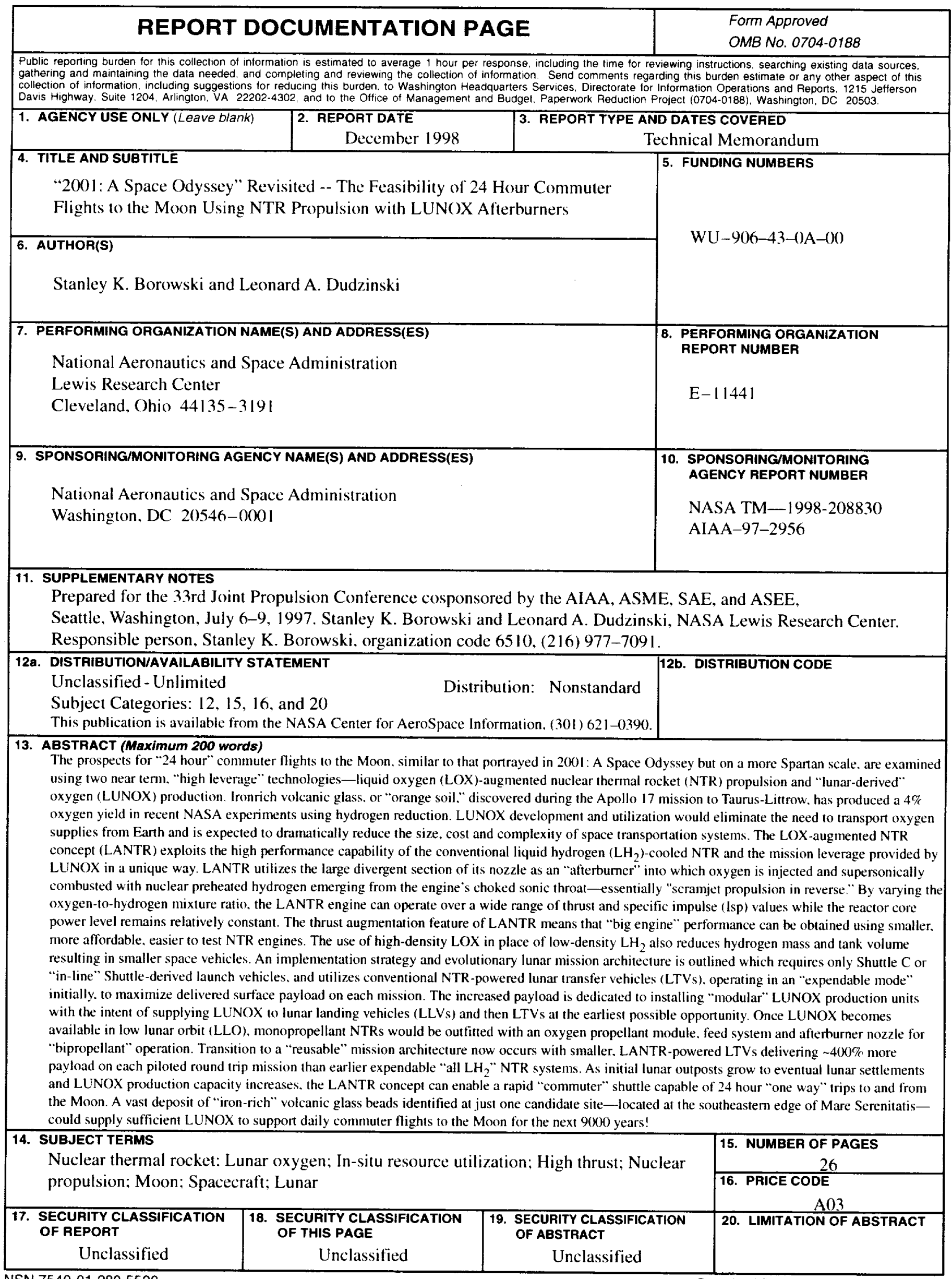

NSN 7540-01-280-5500

Standard Form 298 (Rev. 2-89)

Prescribed by ANSI Std. Z39-18 298-102 